\title{
Effects of Annealing Treatment Prior to Cold Rolling on Delayed Fracture Properties in Ferrite-Austenite Duplex Lightweight Steels
}

\author{
SEOK SU SOHN, HYEJIN SONG, JUNG GI KIM, JAI-HYUN KWAK, \\ HYOUNG SEOP KIM, and SUNGHAK LEE
}

Tensile properties of recently developed automotive high-strength steels containing about $10 \mathrm{wt}$ pet of $\mathrm{Mn}$ and $\mathrm{Al}$ are superior to other conventional steels, but the active commercialization has been postponed because they are often subjected to cracking during formation or to the delayed fracture after formation. Here, the delayed fracture behavior of a ferrite-austenite duplex lightweight steel whose microstructure was modified by a batch annealing treatment at $1023 \mathrm{~K}\left(750{ }^{\circ} \mathrm{C}\right)$ prior to cold rolling was examined by $\mathrm{HCl}$ immersion tests of cup specimens, and was compared with that of an unmodified steel. After the batch annealing, band structures were almost decomposed as strong textures of $\{100\}\langle 011\rangle \alpha$-fibers and $\{111\}\langle 112\rangle \gamma$-fibers were considerably dissolved, while ferrite grains were refined. The steel cup specimen having this modified microstructure was not cracked when immersed in an $\mathrm{HCl}$ solution for 18 days, whereas the specimen having unmodified microstructure underwent the delayed fracture within 1 day. This time delayed fracture was more critically affected by difference in deformation characteristics such as martensitic transformation and deformation inhomogeneity induced from concentration of residual stress or plastic strain, rather than the difference in initial microstructures. The present work gives a promise for automotive applications requiring excellent mechanical and delayed fracture properties as well as reduced specific weight.

DOI: $10.1007 / \mathrm{s} 11661-015-3187-7$

(C) The Minerals, Metals \& Materials Society and ASM International 2015

\section{INTRODUCTION}

RECENTLY, a large amount of Mn and Al has been added to automotive steels to achieve the lightweight effect as well as excellent strength and ductility because the reduction in specific gravity due to substitutional atoms beneficially works for reducing the weight. ${ }^{[1-7]}$ This addition leads to about 10 pet of weight reduction in comparison with transformation-induced plasticity (TRIP) steels or twinning-induced plasticity (TWIP) steels. ${ }^{[8]} \mathrm{Mn}$, an austenite stabilizer, raises the amount of austenite at high temperatures. Al, a ferrite stabilizer, helps to form a duplex structure of ferrite and austenite at high temperatures. ${ }^{[9,10]}$ It also promotes the precipitation of $\kappa$-carbides (composition; $(\mathrm{Fe}, \mathrm{Mn})_{3}-\mathrm{Al}-\mathrm{C}$, perovskite structure) during cooling, and the amount of $\kappa$-carbides varies with contents of $\mathrm{Mn}$ and $\mathrm{C}$ as well as Al. ${ }^{[11-13]}$

SEOK SU SOHN, Postdoctoral Research Associate, and HYEJIN SONG and JUNG GI KIM, Research Assistants, are with the Center for Advanced Aerospace Materials, Pohang University of Science and Technology, Pohang 790-784, Korea. JAI-HYUN KWAK, Senior Principal Researcher, is with the Sheet Products \& Process Research Group, Technical Research Laboratories, POSCO, Kwangyang 545-090, Korea. HYOUNG SEOP KIM and SUNGHAK LEE, Professors, are with the Center for Advanced Aerospace Materials, Pohang University of Science and Technology, and also with Materials Science and Engineering, Pohang University of Science and Technology. Contact e-mail: shlee@ postech.ac.kr

Manuscript submitted November 4, 2014.

Article published online November 18, 2015
Tensile properties of recently developed advanced high-strength steels (AHSSs) for automotive applications are superior to other conventional steels, but the active commercialization of these steels has been postponed because they are easily subjected to the cracking during formation or to the delayed fracture after formation. ${ }^{[14-19]}$ The delayed fracture, a kind of hydrogen embrittlement, is one of the major issues in developments of AHSSs because resistance to hydrogen embrittlement decreases with increasing strengths. ${ }^{[20,21]}$ Recently, high-Mn TWIP steels containing Al have been developed to improve the formability and to prevent the delayed fracture. Here, Al plays an important role in decreasing twin formation because it works for increasing stacking fault energy. ${ }^{[22,23]}$ Chin et al. ${ }^{[15]}$ reported that the cracking or delayed fracture did not occur during or after the cup formation of an Al-added TWIP steel, whereas it occurred in a high-Mn TWIP steel. These results were explained by the stress concentration at the cup side in the high-Mn steel and by the occurrence of homogeneous twinning in the Al-added steel. Berrahmoune et al. ${ }^{[24]}$ found the delayed fracture after deep drawing of $301 \mathrm{LN}$ austenite steels, and explained it by the localization of residual stresses. However, exact mechanisms behind the delayed fracture are not sufficiently understood in relation to microstructures. This is because deformation mechanisms including TRIP and TWIP, ${ }^{[24-26]}$ residual stresses varied with deformed locations, ${ }^{[27]}$ and hydrogen embrittlement are complicatedly combined. 
Lightweight steels containing about $10 \mathrm{wt}$ pct of $\mathrm{Mn}$ and $\mathrm{Al}$ are newly developed, but studies on the delayed fracture are not conducted yet. Furthermore, methods for systematically evaluating the delayed fracture of lightweight steel sheets and detailed deformation and fracture mechanisms related with the delayed fracture are not studied. For the successful development of lightweight steels, the microstructural modification, which can vary with annealing treatment, should also be established. From these understandings, it is possible to successfully fabricate lightweight steels and to improve their microstructures, mechanical properties, and delayed fracture properties simultaneously. In the present study, therefore, the delayed fracture behavior of a ferrite-austenite duplex lightweight steel whose microstructure was modified by a batch annealing treatment at $1023 \mathrm{~K}\left(750{ }^{\circ} \mathrm{C}\right)$ prior to cold rolling was examined by $\mathrm{HCl}$ immersion tests of cup specimens, and was compared with that of an unmodified steel. The cup-forming process was simulated by using finite element method (FEM) in order to analyze stress and strain distributions in the cup after the cup formation. Delayed fracture mechanisms, which have not been sufficiently verified in conventional lightweight steels, were interpreted by microstructural evolution, planar anisotropy, and concentration of residual stress and plastic strain.

\section{EXPERIMENTAL}

\section{A. Lightweight Steels}

The lightweight steel was fabricated by a vacuum induction melting method, and its chemical composition is $\mathrm{Fe}-0.3 \mathrm{C}-3.5 \mathrm{Mn}-5.8 \mathrm{Al}-(<0.02)(\mathrm{P}+\mathrm{S}) \quad$ (wt pct). The rolling and annealing treatment conditions are illustrated in Figure 1. Thick plates (thickness; $60 \mathrm{~mm}$ ) were hot rolled in the temperature range from $1373 \mathrm{~K}$ to $1173 \mathrm{~K}\left(1100{ }^{\circ} \mathrm{C}\right.$ to $\left.900{ }^{\circ} \mathrm{C}\right)$ after homogenization at $1473 \mathrm{~K}\left(1200{ }^{\circ} \mathrm{C}\right)$ for 1 hour to produce 3 -mm-thick plates, and were cooled in a furnace from $923 \mathrm{~K}$ $\left(650{ }^{\circ} \mathrm{C}\right)$ after holding at this temperature for 1 hour in order to simulate a coiling procedure. The hot-rolled steel plates were rolled at room temperature to make 1 -mm-thick steel sheets. Some hot-rolled plates were batch annealed at $1023 \mathrm{~K}\left(750^{\circ} \mathrm{C}\right)$ for 1 hour in a furnace prior to cold rolling. The cold-rolled sheets were intercritically annealed at $1103 \mathrm{~K}\left(830^{\circ} \mathrm{C}\right)$ for $1 \mathrm{~min}$ in a continuous annealing simulator (model; CAS-AY-II, Ulvac-RIKO, Inc., Japan) to form a ferrite-austenite duplex microstructure, and then were cooled to room temperature at a rate of $-14 \mathrm{~K} / \mathrm{s}$ to avoid the decomposition of austenite. For convenience, the intercritically annealed duplex lightweight steel sheets with and without batch annealing prior to cold rolling are referred to as 'A-DL' and 'DL,' respectively.

Effects of $\mathrm{Al}$ addition on weight reduction are attributed to the lattice expansion and the low atomic weight of substitutional solution. ${ }^{[5]}$ The density of the present steel was measured to be $7.19 \mathrm{~g} \mathrm{~cm}^{-3}$, by a densitometry (Mettler-Toledo XP205, Mettler-Toledo AG, Switzerland) on the basis of the Archimedes Principle, which shows an apparent reduction of about 9 pct in comparison to pure Fe.

\section{B. Microstructural Analysis}

Phases present in the specimens were identified by $\mathrm{X}$-ray diffraction $\left(\mathrm{XRD}, \mathrm{Cu} \mathrm{K}_{\alpha}\right.$ radiation, scan rate; 2 deg $\min ^{-1}$, scan step size; $0.02 \mathrm{deg}$ ). Their volume fractions were measured by the direct comparison method using XRD analysis. ${ }^{[10]}$ Integrated intensities of $(200) \alpha$ and $(211) \alpha$ peaks and (220) $\gamma$ and (311) peaks were used for this XRD method. Electron back-scatter diffraction (EBSD) analysis (step size; $0.2 \mu \mathrm{m}$ ) was conducted by a field emission scanning electron microscope (FE-SEM, Quanta 3D FEG, FEI Company, USA). EBSD specimens were mechanically polished and then electro-polished at room temperature in a solution of $\mathrm{CH}_{3} \mathrm{COOH}$ (92 pct) and $\mathrm{HClO}_{4}$ (8 pct) at an operating voltage of $32 \mathrm{~V}$. The data were then interpreted by orientation imaging microscopy (OIM)

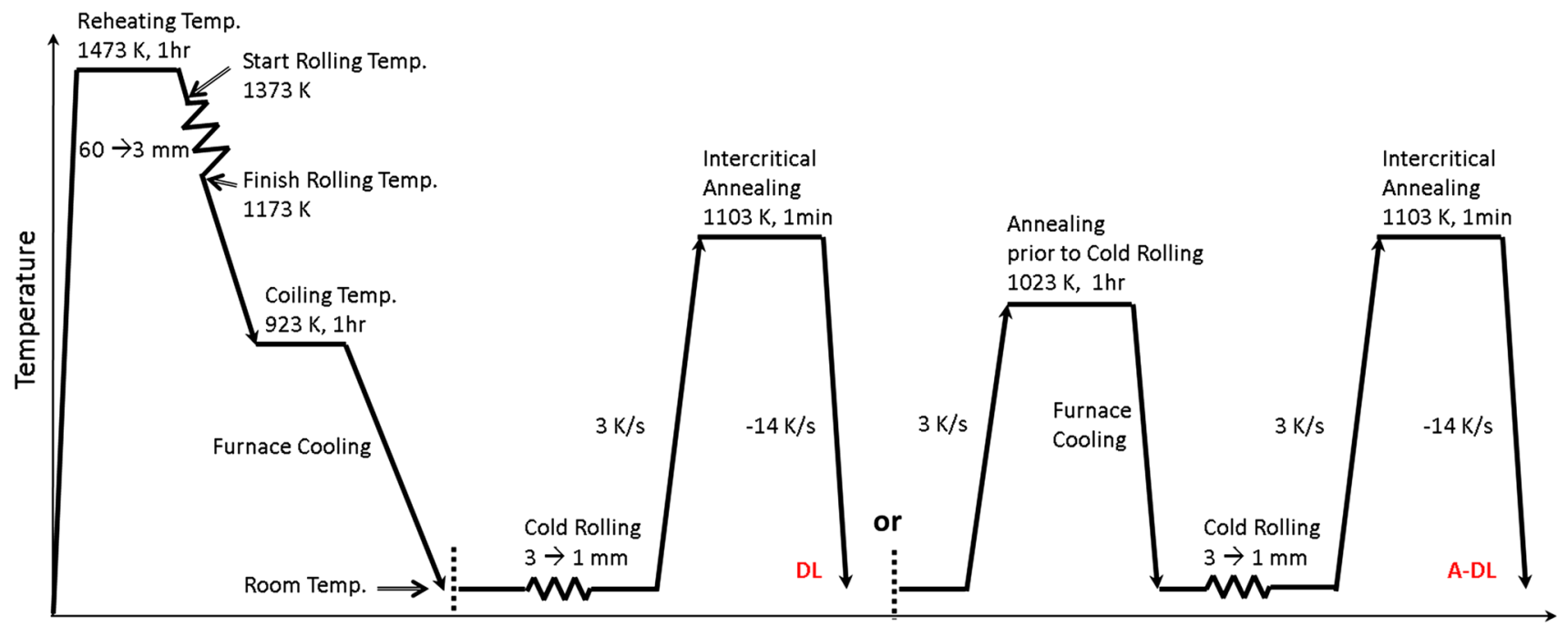

Fig. 1-Schematic illustration of the rolling and annealing conditions for the Fe-0.3C-3.5Mn-5.8Al lightweight steel sheet. 
analysis software (TSL OIM Analysis 5.2) provided by TexSEM Laboratories, Inc. For the TEM observation, specimens were mechanically polished to a thickness of $70 \mu \mathrm{m}$, punched to prepare disk specimens (diameter: $3 \mathrm{~mm}$ ) by a disk cutter, and then electro-polished by a twin-jet polisher (model; Tenupol-5, Struers, Denmark) in a solution of $\mathrm{CH}_{3} \mathrm{COOH}(90 \mathrm{pct})$ and $\mathrm{HClO}_{4}(10 \mathrm{pct})$ to prepare thin foil specimens. The thin foils were observed in a transmission electron microscope (model; 2100, JEOL, Japan) operated at an acceleration voltage of $200 \mathrm{kV}$.

\section{Tensile Test and Measurement of Planar Anisotropy}

Plate-type tensile specimens (gage length; $25 \mathrm{~mm}$, gage width; $6 \mathrm{~mm}$, gage thickness; $1 \mathrm{~mm}$ ) were prepared in the longitudinal, transverse, and 45 deg directions. They were tested at room temperature at a strain rate of $10^{-3} \mathrm{~s}^{-1}$ by a universal testing machine (model; 8801, Instron, Canton, MA, USA) of $100 \mathrm{kN}$ capacity. The strain ratio $(R)$ was measured along the longitudinal, transverse, and $45 \mathrm{deg}$ directions during the tensile test, and then the planar anisotropy $(\Delta R)$ was calculated by the following equations according to the ASTM Standard E 517-00. ${ }^{[28]}$

$$
\begin{gathered}
R=\varepsilon_{w} / \varepsilon_{t} \\
\Delta R=\left(R_{0}+R_{90}-2 R_{45}\right) / 2
\end{gathered}
$$

Here, $\varepsilon_{\mathrm{w}}$ and $\varepsilon_{\mathrm{t}}$ are width and thickness strains, respectively. The $R$ value is generally used as an indicator of formability, and the difference between individual $R$ values $(\Delta R)$ reveals a true extent of non-uniform extension. The tensile test and measurement of planar anisotropy were conducted three times for each datum point.

\section{Cup-Forming Test and $\mathrm{HCl}$ Immersion Test}

The constant loading test and slow strain rate tension test, which have been mainly used for evaluating AHSS bolts, are not widely used for AHSS sheets. ${ }^{[29,30]}$ This is because the above uniaxial deformation tests are not reliable to predict risks of hydrogen embrittlement in actual automotive parts with considering influences of complex forming modes. ${ }^{[30]}$ In the present study, thus, cup-forming tests were conducted on steel sheet discs of $90 \mathrm{~mm}$ in a diameter having machined edge under a sheet holder force of $30 \mathrm{kN}$ by a universal sheet metal testing machine of $100 \mathrm{kN}$ capacity (model; 145, Erichsen, Hemer, Germany). The punch stroke, drawing ratio, and punch speed were $60 \mathrm{~mm}, 1.8$, and $230 \mathrm{~mm} /$ min, respectively. In order to compare resistance to delayed fracture, cup specimens were immersed in a $0.1 \mathrm{M} \mathrm{HCl}$ solution until they were cracked. Here, the $\mathrm{HCl}$ immersion test was used to shorten the time for delayed fracture. After checking the crack initiation of the cup specimen, the time for delayed fracture was measured. In order to analyze microstructural change after the cup-forming test, the cup rim area was sectioned and then examined by XRD. The $\mathrm{HCl}$ immersion test and XRD measurement were conducted five times for each datum point.

\section{E. Hydrogen Charging and Thermal Desorption Analysis}

In order to analyze the amount of hydrogen in the $\mathrm{HCl}$-immersed steel cups at the time of fracture, 10-pct pre-strained tensile specimen was charged in a $0.1 \mathrm{M}$ $\mathrm{HCl}$ solution until delayed fracture of the steel cups occurred. After the hydrogen charging, the amount of diffusible hydrogen content was quantified by thermal desorption analysis (TDA) using a gas chromatograph (model; Agilent 7890A, Agilent Technologies, USA). The TDA was conducted at a heating rate of $100 \mathrm{~K} / \mathrm{h}$ up to a maximum temperature of $773 \mathrm{~K}\left(500{ }^{\circ} \mathrm{C}\right)$ under an environment of $\mathrm{He}$ as a carrier gas. The amount of hydrogen gas released from the hydrogen-charged specimen was analyzed at an interval of $3 \mathrm{~min}$. Diffusible and non-diffusible hydrogen contents were defined as the sum of desorbed hydrogen content within the first and second peaks of hydrogen desorption rate curve, respectively. ${ }^{[31]}$

\section{RESULTS}

\section{A. Microstructure}

EBSD phase color maps of the DL and A-DL steels are shown in Figures 2(a) and (b), respectively. The DL steel exhibits a basically banded structure because austenite bands are aligned parallel to the rolling direction (Figure 2(a)). Inside austenite bands, a number of austenite grains are formed in a particle shape in the ferrite matrix. In the A-DL steel, however, the band structure is considerably decomposed as band boundaries are not clearly defined. Most of austenite grains are relatively homogeneously distributed in the ferrite matrix. Ferrite grains of the DL steel are larger (about $24 \mu \mathrm{m}$ ) than those of the A-DL steel (about $7 \mu \mathrm{m}$ ), while austenite grain sizes are almost similar $(0.6$ to $0.8 \mu \mathrm{m})$ in both steels. X-ray diffraction patterns of the DL and A-DL steels are provided in Figure 2(c). Peaks of ferrite and austenite are observed with very low peaks of $\kappa$-carbide in both steels. Volume fractions of austenite were measured by the direct comparison method, and are shown above each XRD pattern. The austenite volume fractions are similar at about 16 pet in both steels. SEM micrographs of the DL and A-DL steels are shown in Figures 3(a) and (b), respectively. There are very small fractions of $\kappa$-carbide within ferrite grains.

In order to investigate the crystal orientation of many ferrite grains, the low-magnification EBSD analysis was performed. Inverse pole figure (IPF) maps and orientation distribution functions (ODFs) in Euler space $\left(\varphi_{2}=45 \mathrm{deg}\right.$ section) of ferrite in the DL and A-DL steels are shown in Figures 4(a) through (d). Ferrite grains of the DL steel are coarse, as aforementioned in Figure 2(a), and seem to form a strong texture aligned along the rolling direction (Figure 4(a)). The A-DL steel shows the fine grain size and relatively weak texture 

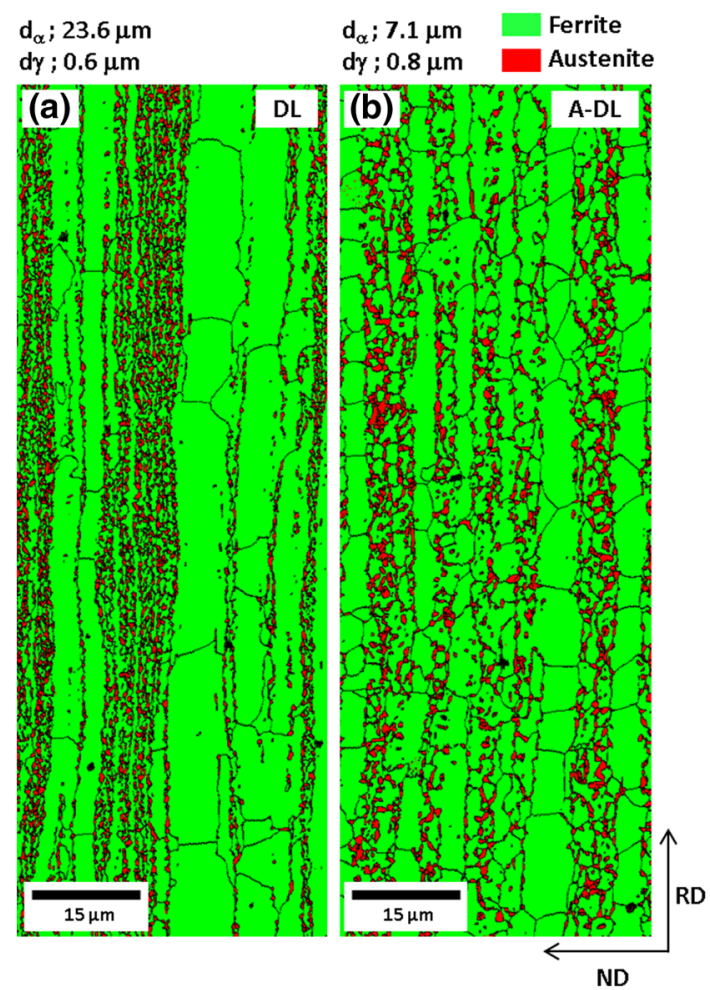

(c)

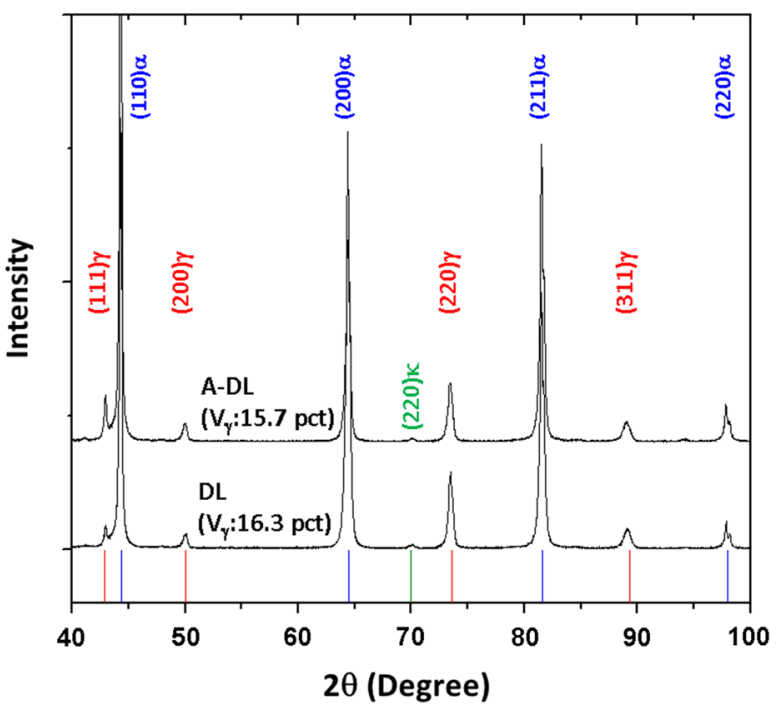

Fig. 2-(a) and (b) EBSD phase color maps, and (c) X-ray diffraction patterns of the DL and A-DL steels.
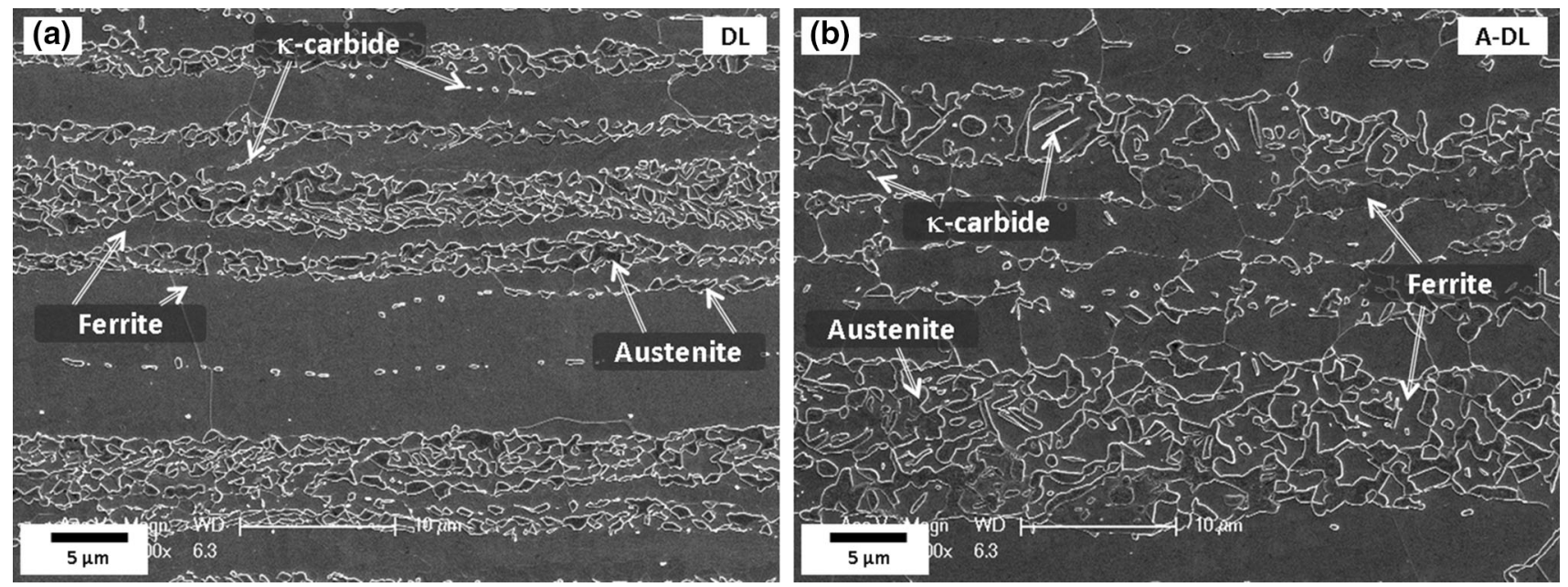

Fig. 3-SEM micrographs of the (a) DL and (b) A-DL steels showing very small fraction of $\kappa$-carbide with ferrite-austenite.

(Figures 2(b) and 4(b)). According to the ODF analysis data, the DL steel has the remarkable preferred orientation because $\alpha$-fibers of $\{100\}\langle 011\rangle$ and $\gamma$-fibers of $\{111\}\langle 112\rangle$ are well developed (Figure 4(c)). In the A-DL steel, $\alpha$-fibers are developed, but their intensity is very low (Figure 4(d)), which indicates the considerable dissolution of textures.

\section{B. Tensile and Planar Anisotropy Properties}

Figures 5(a) and (b) show room-temperature tensile stress-strain curves along the longitudinal, transverse, and 45 deg directions for the DL and A-DL steels. From the curves, the yield strength, ultimate tensile strength, and elongation were measured, and the results are summarized in Table I together with planar anisotropy $(\Delta R)$. The yield and tensile strengths of the DL steel are higher by 50 to $60 \mathrm{MPa}$ than those of the A-DL steel, while the elongation is not varied much. In both steels, the strengths decrease in the order of the transverse, longitudinal, and $45 \mathrm{deg}$ directions. The differences in directional tensile properties are smaller in the A-DL steel than in the DL steel. This can be confirmed by $\Delta R$ values (0.2 and 0.57 in the A-DL and DL steels, respectively). 

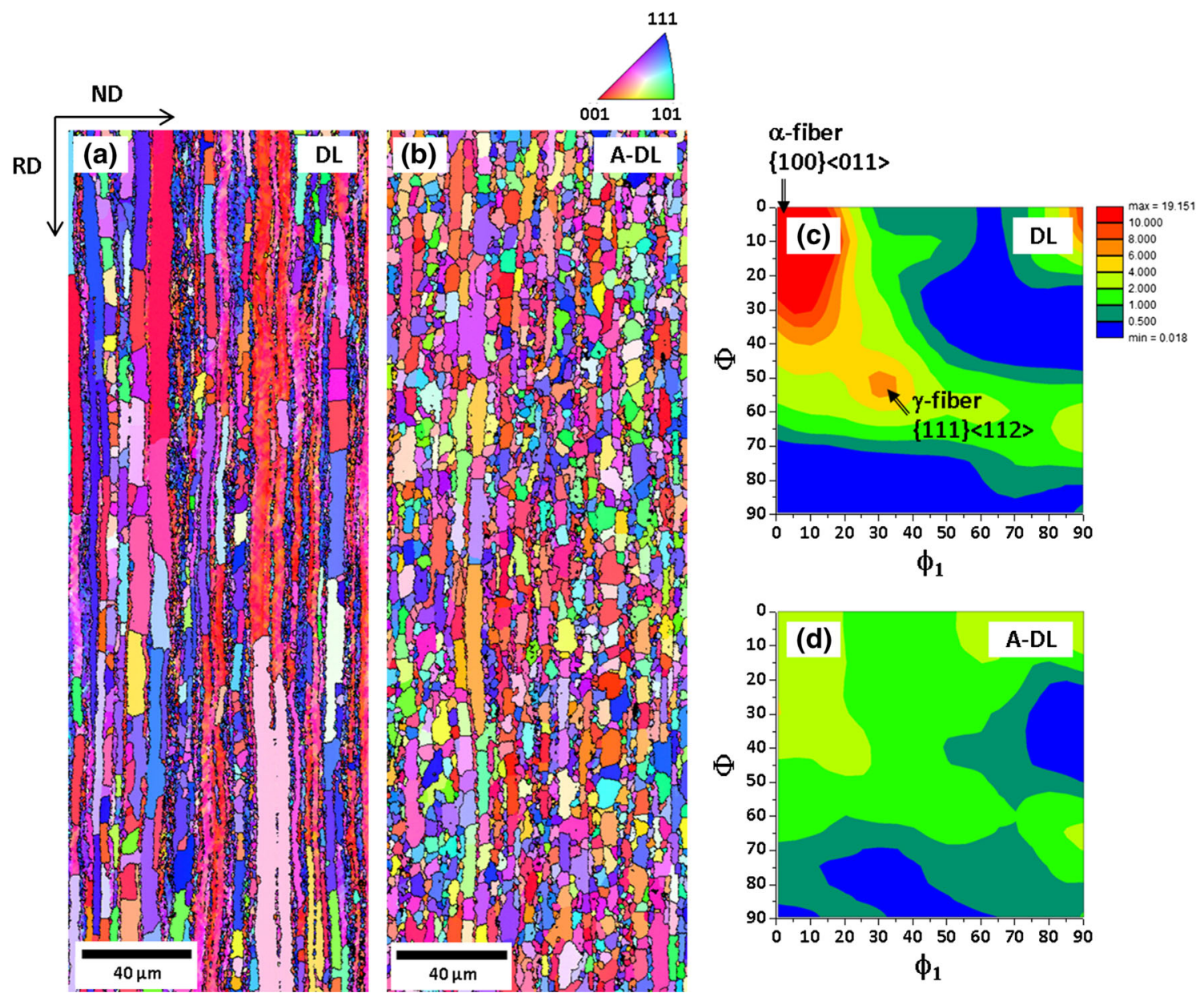

Fig. $4-(a)$ and $(b)$ EBSD inverse pole figure (IPF) maps, and $(c)$ and $(d)$ orientation distribution functions $(\mathrm{ODFs})$ in Euler space $\left(\varphi_{2}=45\right.$ deg section) of ferrite for the DL and A-DL steels.

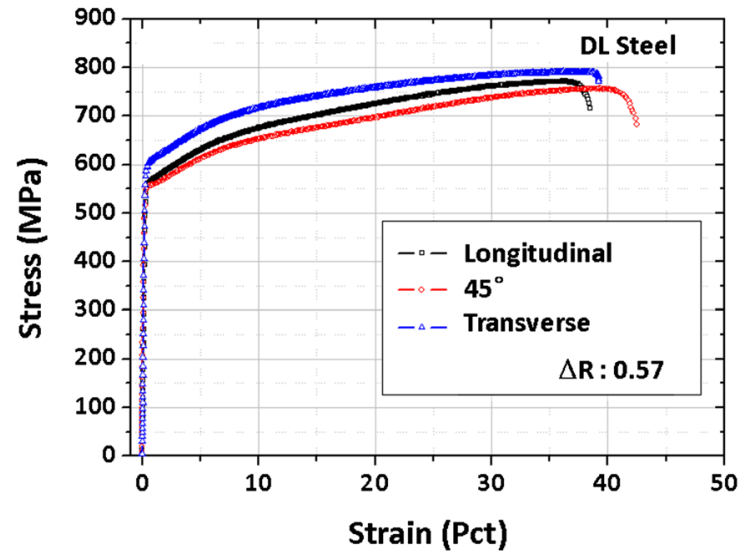

(a)

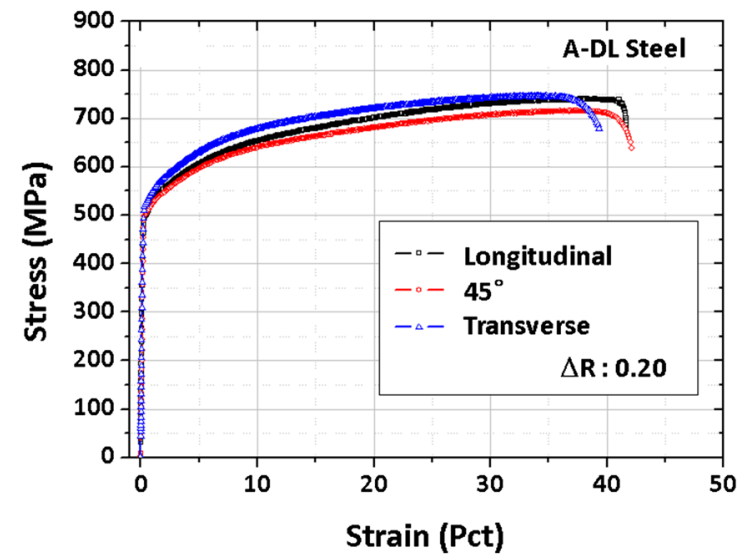

(b)

Fig. 5-Room-temperature tensile stress-strain curves along the longitudinal, transverse, and 45 deg directions for the $(a)$ DL and $(b)$ A-DL steels. The planar anisotropy $(\Delta R)$ values measured from the curves are 0.57 and 0.2 in the DL and A-DL steels, respectively.

\section{Delayed Fracture Properties}

Figures 6(a) and (b) show photographs of the cup specimens of the DL and A-DL steels. The earing phenomenon, which means the inhomogeneity of cup height, occurs in the DL steel cup. When considering the angle deviated from the longitudinal direction, the cup height is high in the 45 deg direction, while it is low in the 0 and 90 deg directions. However, it is not found in the A-DL steel cup. After the $\mathrm{HCl}$ immersion test of the cup specimens, the time for delayed fracture was 
Table I. Room-Temperature Tensile Properties in the Longitudinal, Transverse, and 45 deg Directions and Planar Anisotropy $(\Delta R)$ of the DL and A-DL Steels

\begin{tabular}{|c|c|c|c|c|c|}
\hline Steel & Tensile Direction & Yield Strength (MPa) & Tensile Strength (MPa) & Elongation (pct) & $\Delta R$ \\
\hline \multirow[t]{3}{*}{$\mathrm{DL}$} & Longitudinal & $561 \pm 4$ & $771 \pm 11$ & $38.5 \pm 1.1$ & \multirow[t]{3}{*}{$0.57 \pm 0.02$} \\
\hline & $45 \mathrm{deg}$ & $554 \pm 11$ & $757 \pm 12$ & $42.5 \pm 2.3$ & \\
\hline & Transverse & $599 \pm 7$ & $791 \pm 3$ & $39.2 \pm 1.3$ & \\
\hline \multirow[t]{3}{*}{ A-DL } & Longitudinal & $503 \pm 5$ & $741 \pm 5$ & $41.7 \pm 0.9$ & \multirow{3}{*}{$0.2 \pm 0.09$} \\
\hline & $45 \mathrm{deg}$ & $504 \pm 12$ & $716 \pm 12$ & $42.2 \pm 1.4$ & \\
\hline & Transverse & $526 \pm 9$ & $747 \pm 8$ & $39.4 \pm 1.1$ & \\
\hline
\end{tabular}

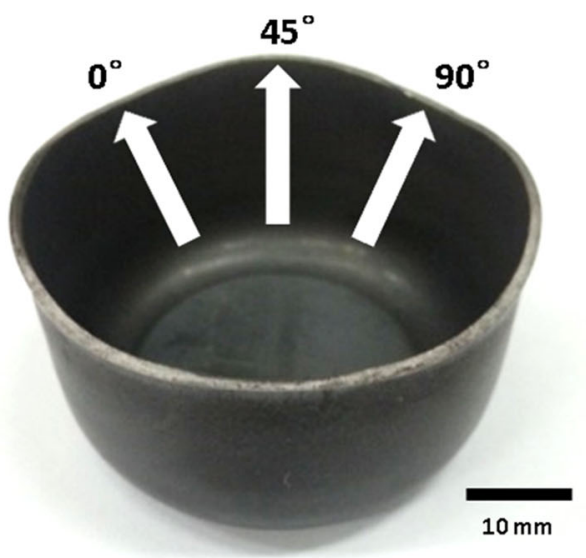

(a) DL

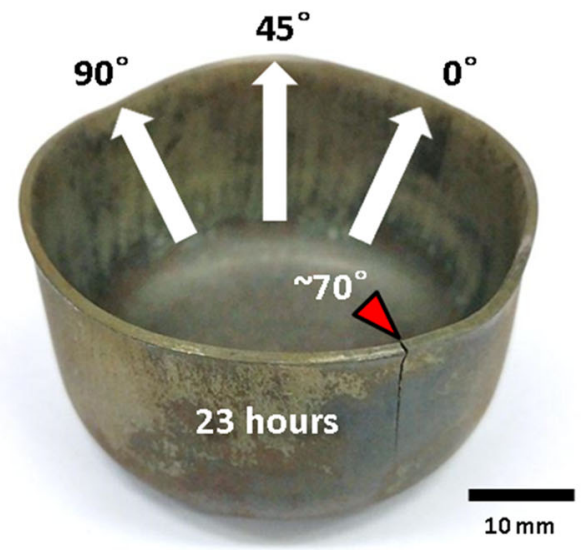

(c) DL

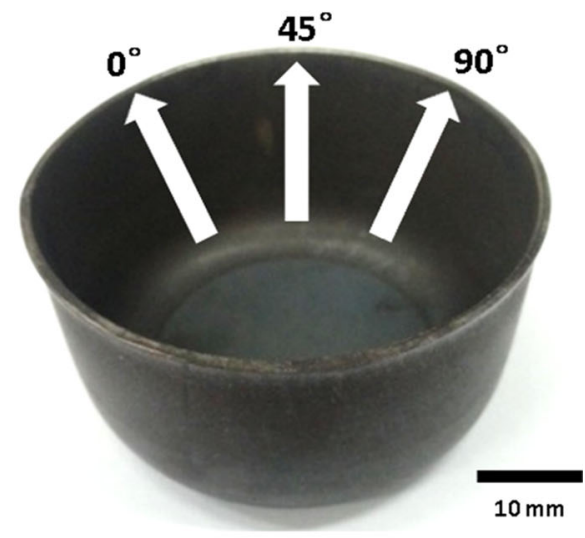

(b) A-DL

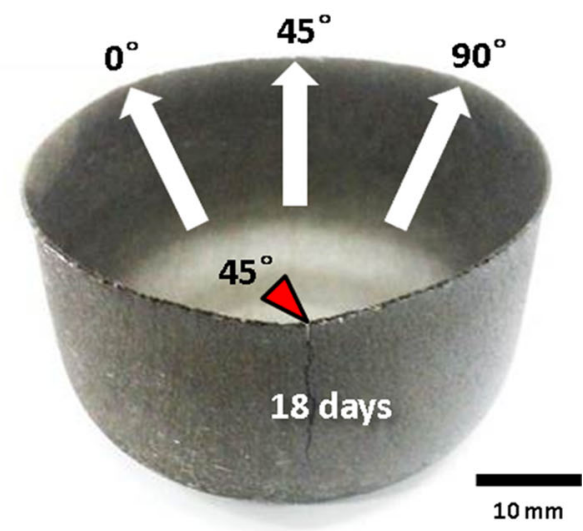

(d) A-DL

Fig. 6- Photographs of the cup specimens before and after the $\mathrm{HCl}$ immersion test of the $(a)$ and (c) DL and (b) and (d) A-DL steels. The DL steel cup was cracked in the approximately $70 \mathrm{deg}$ direction after the 23 -hour immersion, whereas the A-DL steel cup was cracked in the 45 deg direction after the 18-day immersion.

measured, and the cup specimens are shown in Figures 6(c) and (d). The DL steel cup underwent the delayed fracture when immersed for 23 hours as indicated by a red arrow in Figure 6(c), whereas the A-DL steel cup was cracked after the 18-day immersion (Figure 6(d)). This result indicates that delayed fracture properties in the A-DL steel are better than those of the DL steel cup. The locations of crack initiation in the DL and A-DL steels are frequently seen in the approximately $70 \mathrm{deg}$ direction and $45 \mathrm{deg}$ direction to the rolling direction, respectively.
Hydrogen desorption rate curves obtained from the thermal desorption analysis of the DL and A-DL steels are shown in Figure 7. In both steels, the temperatures showing the maximum peak of diffusible and non-diffusible hydrogen-trapping sites are $363 \mathrm{~K}$ and $773 \mathrm{~K}$ $\left(90^{\circ} \mathrm{C}\right.$ and $\left.500{ }^{\circ} \mathrm{C}\right)$, respectively. The amount of diffusible and non-diffusible hydrogen contents are about 4.6 and $0.8 \mathrm{ppm}$, respectively. These results indicate that the hydrogen desorption behavior is almost the same in both steels, although their delayed fracture properties are different. 


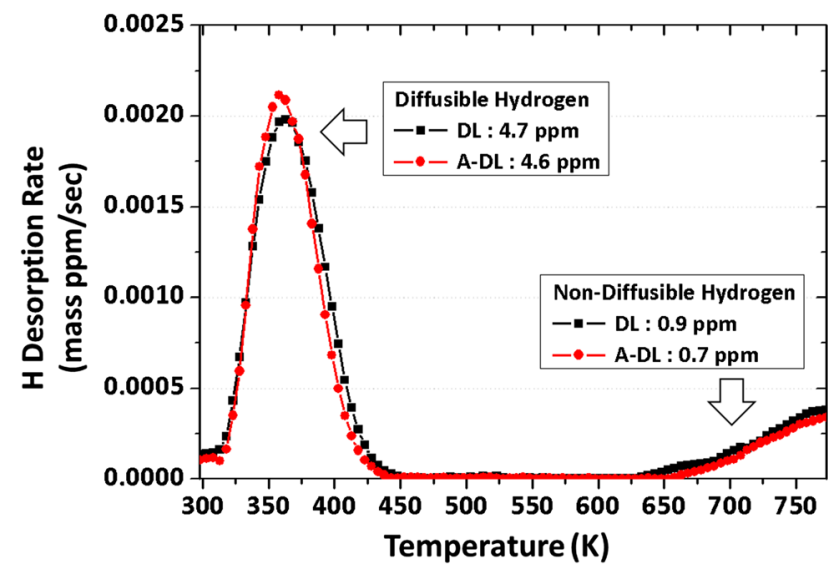

Fig. 7-Hydrogen desorption rate curves obtained from the thermal desorption analysis of the DL and A-DL steels. In both steels, the temperatures showing the maximum peak of diffusible and non-diffusible hydrogen-trapping sites are about $363 \mathrm{~K}$ and $773 \mathrm{~K}\left(90{ }^{\circ} \mathrm{C}\right.$ and $500{ }^{\circ} \mathrm{C}$ ), respectively.

\section{DISCUSSION}

The simple addition of batch annealing treatment at $1023 \mathrm{~K}\left(750^{\circ} \mathrm{C}\right)$ prior to cold rolling (Figure 1) in the DL steel results in plausible microstructural modification in the A-DL steel. Ferrite grains are refined (Figure 2(b)), and strong textures are considerably dissolved (Figures 4(b) and (d)) by the annealing treatment, while volume fraction and size of austenite are not varied much (Figures 2(a) through (c)). In addition, the band structure is considerably decomposed as austenite grains are relatively homogeneously distributed in the ferrite matrix.

This microstructural modification is closely related with hot-rolled microstructures. After the hot rolling, the steel consists of ferrite matrix and $\kappa$-carbides in a banded shape as verified in previous researches. ${ }^{[32,33]}$ The ferrite matrix shows coarse grain size without any carbide, and $\kappa$-carbide band shows lamellar structure of ferrite and $\kappa$-carbide. After this, hot-rolled plate is rolled at room temperature, the lamellar $\kappa$-carbides are broken and deformed. During subsequent critical-annealing, austenite a few micrometers in size can be formed since these fine $\kappa$-carbides act as primary sites for austenite nucleation during annealing. This fine austenite is retained at room temperature because of increased thermal stability against martensitic transformation by grain size effect. Finally, banded structures are maintained with coarse ferrite band and austenite band transformed from $\kappa$-carbides. This exhibits the microstructure of the DL steel.

During the batch annealing treatment of the hot-rolled plate, however, fine $\kappa$-carbides are precipitated inside ferrite bands, and lamellar $\kappa$-carbides inside $\kappa$-carbide bands are spheroidized. Since most of these $\kappa$-carbides are formed in a form of homogeneously distributed particles, they actively work as nucleation sites of ferrite and austenite during the subsequent intercritical annealing process, and play an important role in grain refinement as a particle-stimulated nucleation mechanism is working. ${ }^{[3,34]} \mathrm{New}$ grains having different orientations from the matrix orientation are formed, and band structures and textures are readily dissolved, unlike in the DL steel. This microstructural modification is quite beneficial for the improvement of plastic formability expressed as planar anisotropy $(\Delta R$ value). The differences in directional tensile properties and $\Delta R$ values are smaller in the A-DL steel than in the DL steel (Table I). Therefore, it should be noted that the present batch annealing treatment plausibly leads to the modification of the final microstructure and to the improvement of plastic formability of duplex lightweight steel sheets.

The delayed fracture readily occurs by the movement and accumulation of diffusible hydrogen atoms into internal defects to reach a certain critical concentration. ${ }^{[35]}$ In general, two kinds of microstructural defects control the hydrogen embrittlement resistance. ${ }^{[31,38]}$ Reversible or diffusible hydrogen-trapping sites such as grain boundaries and dislocations show the low activation energy for hydrogen detrapping. The irreversible or non-diffusible hydrogen-trapping sites contain high-energy barriers for hydrogen detrapping, such as inclusions and voids. An increased number of trap sites, such as grain boundaries or dislocations, can reduce the hydrogen diffusivity and delay the accumulation of hydrogen atoms on potentially embrittled regions. Thus, delayed fracture properties are improved when trapping sites of hydrogen are populated or grain boundary fraction is increased by grain refinement. ${ }^{[36]}$ However, Park et al. ${ }^{[37]}$ reported that the diffusible hydrogen content is almost same when grain size decreases from 79.8 to $6.4 \mu \mathrm{m}$ in high-Mn TWIP steels. Though the grain refinement improves the resistance to hydrogen embrittlement, the delayed fracture mechanism is also related with the decrease in densities of twin boundaries, twin-twin junctions, and twin-grain boundary junctions. In the A-DL steel, diffusible and non-diffusible hydrogen contents are similar (about 4.6 and $0.8 \mathrm{ppm}$, respectively) to those of the DL steel under the same experimental condition to the $\mathrm{HCl}$ immersion test, although the ferrite grain size is reduced from 24 to 7 $\mu \mathrm{m}$. This result on hydrogen contents indicates that the effect of microstructural modification in the A-DL steels on hydrogen permeation is not significant.

According to Takagi et al. ${ }^{[30]}$ the delayed fracture is influenced by material strengths or applied stress and strain states as well as microstructures. Though the difference in strengths of the DL and A-DL steels in not large (30 to $70 \mathrm{MPa}$ ) as shown in Figures 5(a) and (b) and Table I, the earing phenomenon occurs in the DL steel cup, whereas it does not in the A-DL steel cup (Figures 6(a) and (b)). In fact, since automotive steel sheets are plastically formed to meet final shapes of automotive parts, the inhomogeneity of plastic forming, e.g., the earing occurring during the cup formation, should be carefully examined in relation with the delayed fracture of cup specimens.

In order to examine the earing in detail, the height of cup specimen was measured as a function of angle deviated from the longitudinal direction, and the results are shown in Figure 8(a). The cup height is high in the 45 deg direction in the DL steel, thereby clearly showing 


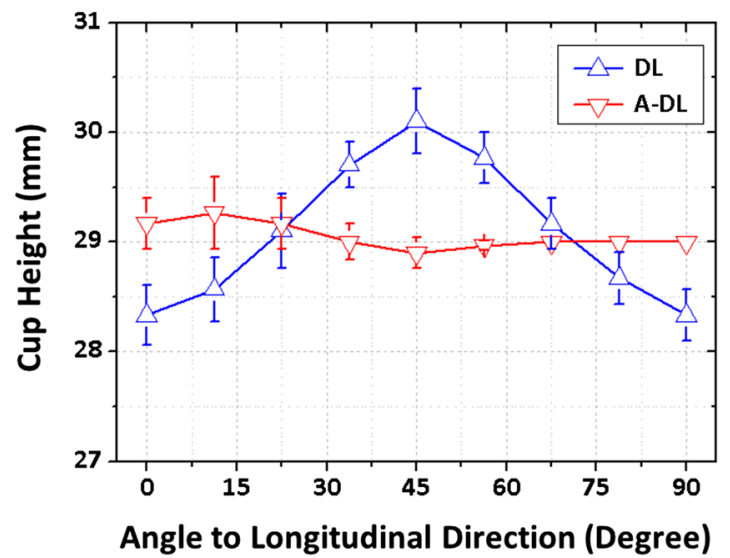

(a)

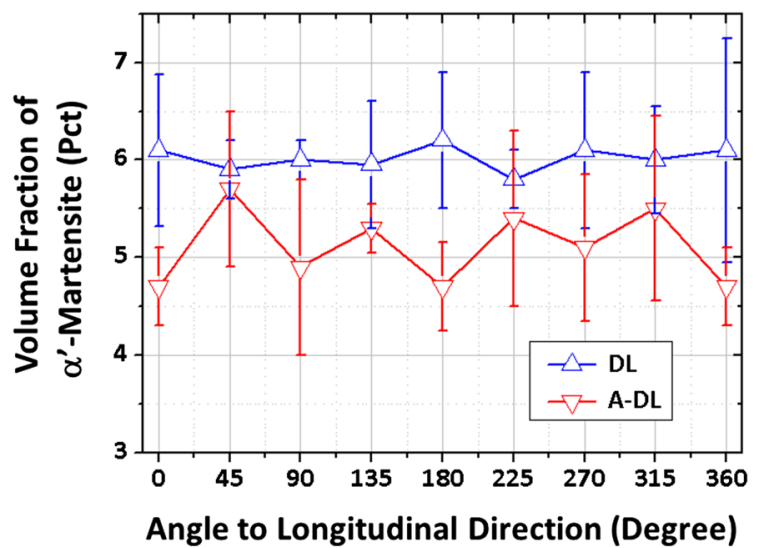

(b)

Fig. 8 - (a) Height of cup specimen and $(b)$ volume fraction of $\alpha^{\prime}$-martensite as a function of angle deviated from the longitudinal direction.

the earing profile, whereas it remains almost constant at about $29 \mathrm{~mm}$ in the A-DL steel. In steel sheets basically having bcc structure, $\{001\}\langle 110\rangle$ component $\left(\varphi_{1}=0 \mathrm{deg}, \phi=0 \mathrm{deg}, \varphi_{2}=45 \mathrm{deg}\right),(111)^{[1-10]} \mathrm{com}-$ ponent $\left(\varphi_{1}=0 \mathrm{deg}, \phi=54.7 \mathrm{deg}, \varphi_{2}=45 \mathrm{deg}\right)$, and (111)[11-2] component $\left(\varphi_{1}=90 \mathrm{deg}, \phi=54.7 \mathrm{deg}\right.$, $\left.\varphi_{2}=45 \mathrm{deg}\right)$ typically appear after hot-rolling and annealing treatments. ${ }^{[39]}$ Among these components, the $\{001\}\langle 110\rangle$ component induces the bilaterally symmetric earing, in which the cup height is high in the $45 \mathrm{deg}$ direction, because of its fourfold symmetry on yield anisotropy. ${ }^{[39]}$ In the A-DL steel, band structures are dissolved, and fine ferrite grains are homogeneously distributed, thereby leading to the small planar anisotropy and the constant height of cup specimen.

The high planar anisotropy generally induces the concentration of residual stress or plastic strain in certain areas such as rim areas of cup specimen due to the inhomogeneity of cup formability, like in the DL steel. ${ }^{[40,41]}$ In order to investigate effects of plastic strain and residual stress during the cup-forming test, three-dimensional elasto-plastic finite element method (FEM) simulations were performed by using a commercial package, ABAQUS (ver. 6.9/EF2, Dassault Systemes Simulia, Inc., Seoul, Korea) with a standard scheme. Dimensions of deep drawing models were same to experimental ones. Based on Hill's potential function, ${ }^{[42]}$ anisotropic properties were calculated by the following equations:

$$
\begin{gathered}
R_{11}=1 \\
R_{22}=\sqrt{ }\left(\left(R_{90}\left(r_{0}+1\right)\right) /\left(R_{0}\left(R_{90}+1\right)\right)\right) \\
\mathrm{R}_{33}=\sqrt{ }\left(\left(\mathrm{R}_{90}\left(\mathrm{R}_{0}+1\right)\right) /\left(\left(\mathrm{R}_{0}+\mathrm{R}_{90}\right)\right)\right) \\
\mathrm{R}_{23}=\sqrt{ }\left(\left(3\left(\mathrm{r}_{0}+1\right) \mathrm{R}_{90}\right) /\left(\left(2 \mathrm{r}_{45}+1\right)\left(\mathrm{R}_{0}+\mathrm{R}_{90}\right)\right)\right)
\end{gathered}
$$

where $R_{0}, R_{45}$, and $R_{90}$ are $R$ values measured from the tensile test, and $R_{11}, R_{22}, R_{33}$, and $R_{23}$ are converted $R$ values for the anisotropy FEM simulations. ${ }^{[43]}$
Simulated equivalent plastic strain contours along the cup rim area after the cup-forming test of the DL and A-DL steels are calculated as a function of angle deviated from the longitudinal direction, as shown in Figure 9(a). Though the overall plastic strain distributions are similar in both the steels, i.e., showing highly localized strain values in the cup rim area, the large earing appears in the DL steel cup specimen, which can be corresponded with the actual cup-forming test results (Figure 6(a)). Equivalent plastic strains in the A-DL steel are relatively homogeneous in the range of about 0.55. In the DL steel, however, equivalent plastic strains are highly localized in the 15 and 75 deg directions in a strain level of about 0.75 , although the overall strain level is lower than that of the A-DL steel. This strain localization is caused by the anisotropy of materials because highly anisotropic materials show low strains at the point of high cup specimen height and high strains at the point of low cup specimen height. ${ }^{[4]}$ Since the profile of cup specimen height is generally matched with distributions of $R$ value, the deformation instability as well as large deviation of $R$ value occurs during the cup formation, thereby leading to high possibility of delayed fracture after the cup formation.

Simulated residual hydrostatic stress contours along the cup rim area after the cup-forming test are shown in Figure 9(b). Here, residual hydrostatic stresses formed at the cup edge where the radial crack initiates during the delayed fracture test are calculated as a function of angle deviated from the longitudinal direction. Overall residual hydrostatic stresses are ranged from 100 to 150 $\mathrm{MPa}$ in the A-DL steel, whereas they are very high (200 MPa or higher) in the 15 and 75 deg directions in the DL steel. Considering the crack formation in the approximately $70 \mathrm{deg}$ direction in the DL steel (Figure 6(c)), the crack initiates at regions of highly localized residual tensile stress, which can also be accurately estimated from FEM simulations.

The DL and A-DL steels having composition of Fe-0.3C-3.5Mn-5.8Al basically show excellent mechanical properties by the TRIP mechanism $\left(\gamma \rightarrow \alpha^{\prime}\right.$-martensite transformation during the deformation). ${ }^{[33]}$ Though the hydrogen desorption behavior is almost same in 

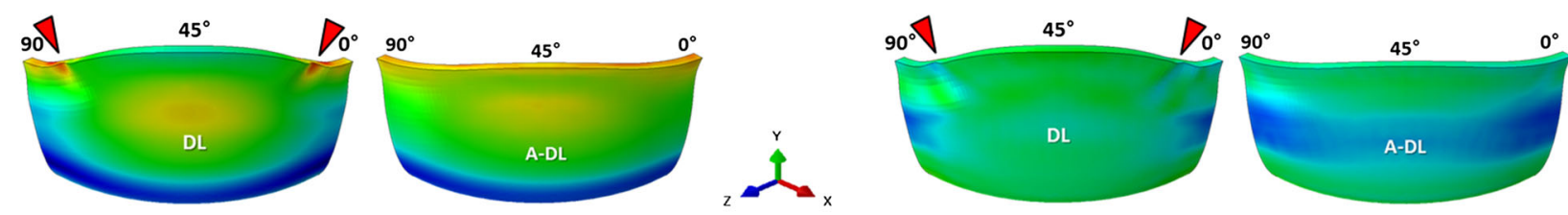

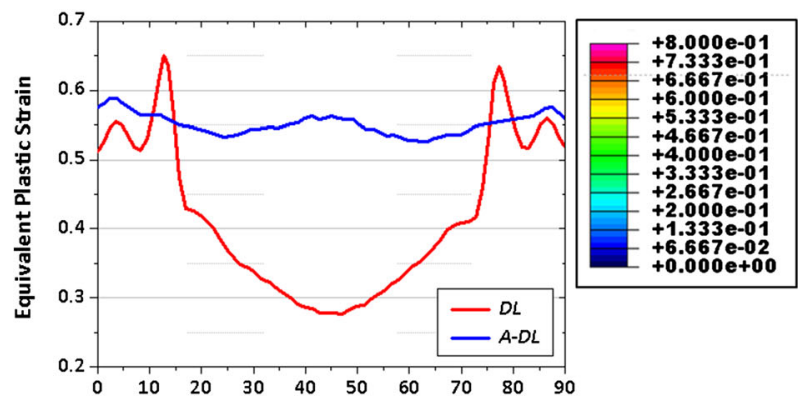

Angle Deviated from Longitudinal Direction (Degree)

(a)

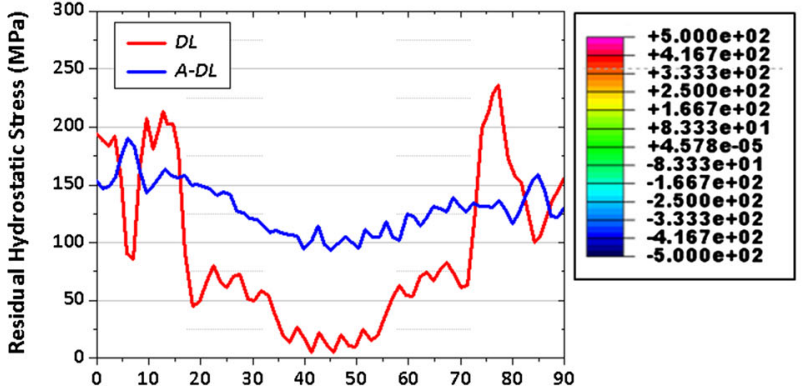

Angle Deviated from Longitudinal Direction (Degree)

(b)

Fig. 9- Simulated contours of $(a)$ equivalent plastic strain and $(b)$ residual hydrostatic stress after the cup-forming test of the DL and A-DL steels as a function of angle deviated from the longitudinal direction.
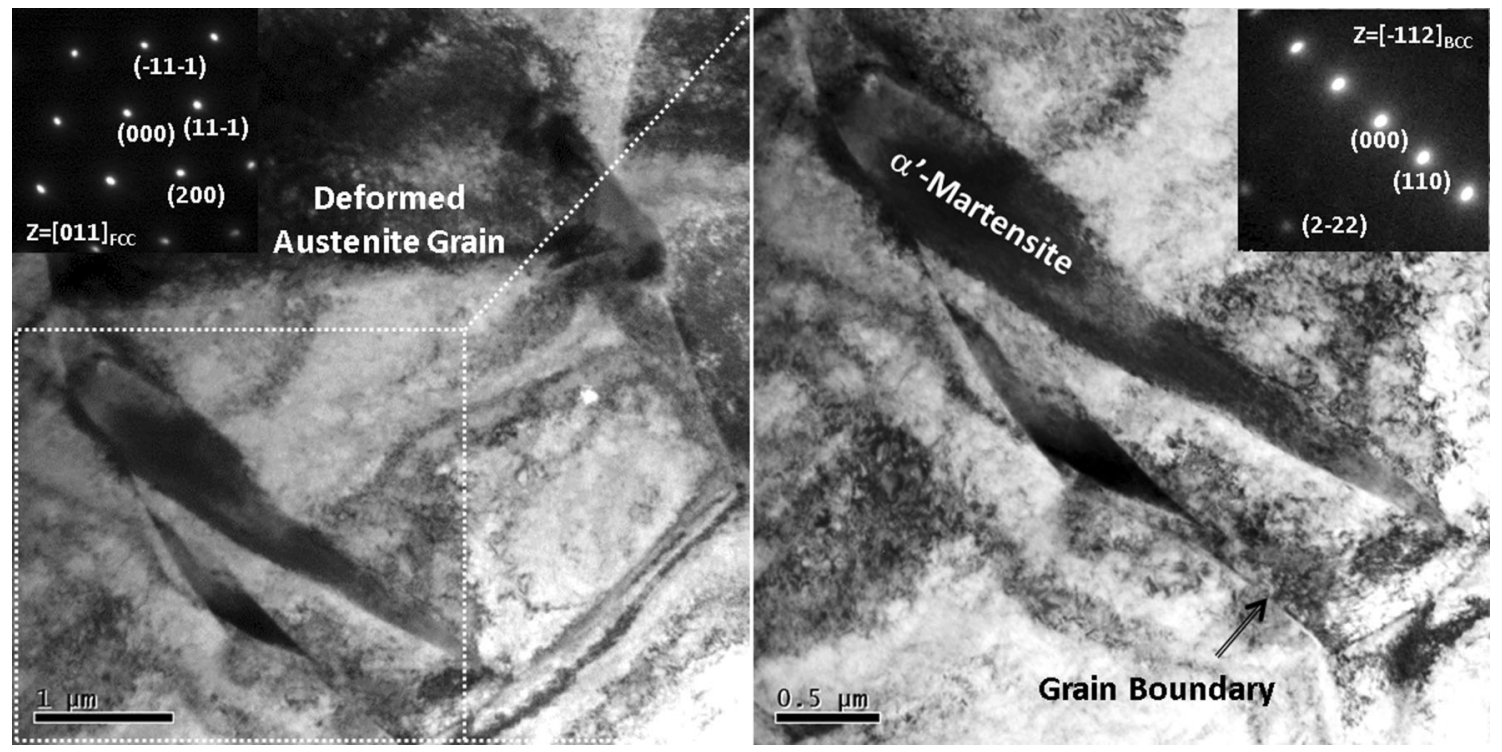

Fig. 10-TEM bright field images of a deformed austenite grain and an $\alpha^{\prime}$-martensite in the rim area of the DL steel cup specimen. Two insets show selected area diffraction (SAD) patterns taken along the [011] zone axis of an austenite grain and along the [-112] zone axis of bcc phase.

both steels (Figure 7), delayed fracture properties vary with the formation of $\alpha^{\prime}$-martensite because the deformation becomes inhomogeneous after the cup formation, as shown in FEM simulation results of Figure 9(a). In order to confirm the TRIP mechanism, TEM analysis was conducted on the rim area of the DL steel cup specimen, as shown in Figure 10. An inset of Figure 10 shows a selected area diffraction (SAD) pattern taken along the [011] zone axis of an austenite grain. The austenite grain is deformed by the dislocation slip mechanism without forming any deformation twins. When the left side of the deformed austenite grain is magnified, $\alpha^{\prime}$-martensite is found at the austenite grain boundary, as confirmed by an SAD pattern taken along the $[-112]$ zone axis of bcc phase.

Volume fraction of $\alpha^{\prime}$-martensite was measured by the direct comparison method after samples were collected from the cup rim area, and are plotted as a function of angle deviated from the longitudinal direction, as shown in Figure 8(b). The simulated equivalent plastic strain distribution is more inhomogeneous in the DL steel than in the A-DL steel (Figure 9(a)), but the volume fraction of strain-induced transformed martensite is more inhomogeneous in the A-DL steel. It is well known that the austenite stability against strain-induced martensitic transformation is dependent on grain size and chemical 
$0^{\circ}$

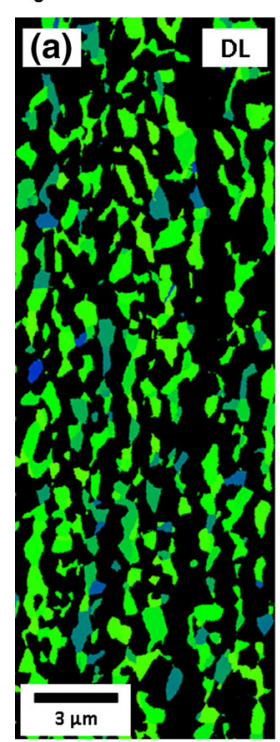

$45^{\circ}$

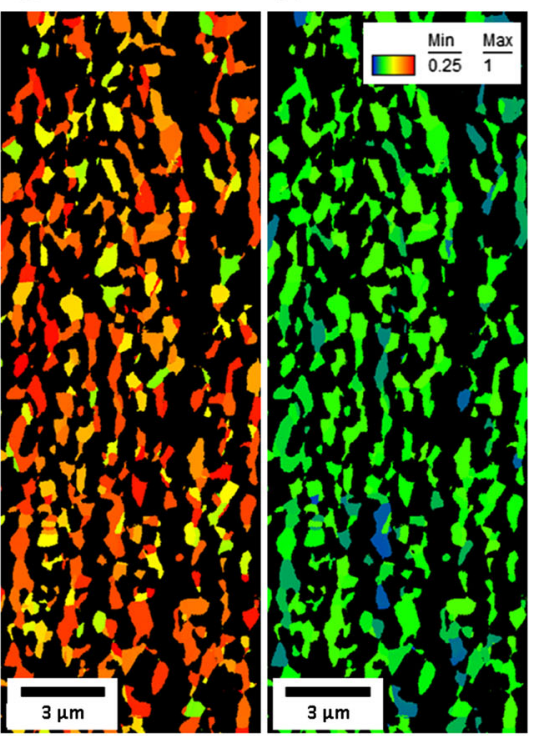

$0^{\circ}$

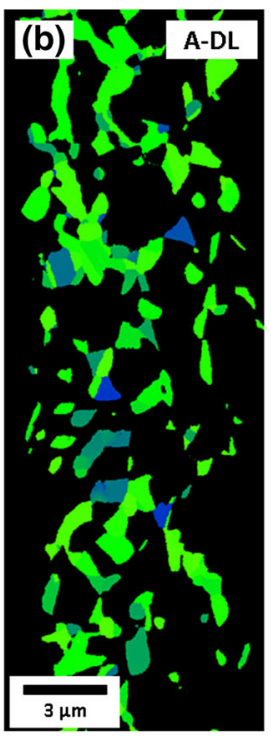

$45^{\circ}$

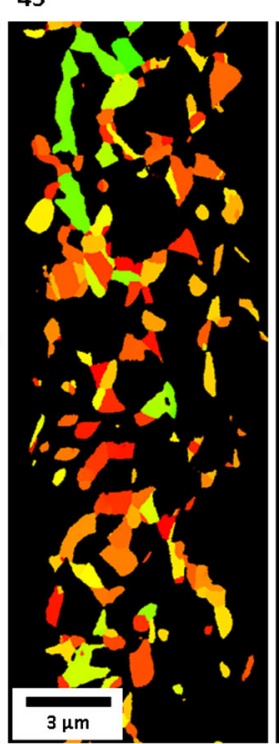

$90^{\circ}$

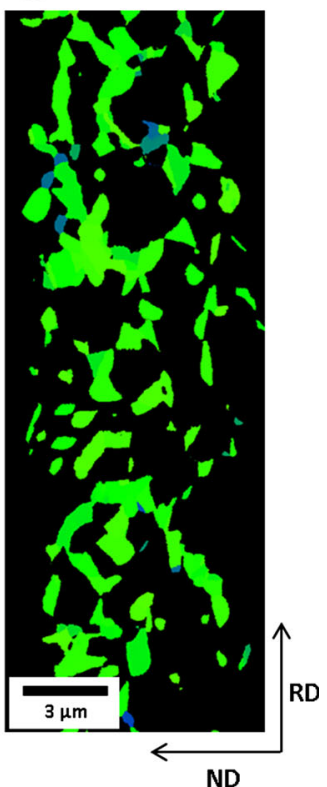

Fig. 11-EBSD Schmid factor maps of austenite in the 0, 45, and 90 deg directions during the cup formation for the (a) DL and (b) A-DL steels. In both steels, Schmid factor is low $(0.27$ to 0.5$)$ in the 0 and 90 deg directions, whereas it is high $(0.48$ to 1.0$)$ in the 45 deg direction.

composition. ${ }^{[45]}$ When the tensile loading directions are varied, like in the present study, Schmid factor plays an important role in austenite stability. ${ }^{[46]}$ Considering that the martensitic transformation is triggered by the supply of strain energy as a consequence of dislocation pile-ups at strong barriers such as grain boundaries, ${ }^{[4-49]}$ the martensitic transformation preferentially occurs in regions having high resolved shear stresses, i.e., high Schmid factors, even in the same grain size and composition conditions. Figures 11(a) and (b) show EBSD Schmid factor maps of austenite in the 0,45 , and $90 \mathrm{deg}$ directions during the cup formation. In both steels, Schmid factor is low $(0.27$ to 0.5$)$ in the 0 and $90 \mathrm{deg}$ directions, whereas it is high $(0.48$ to 1.0$)$ in the 45 deg direction.

In the DL steel, the volume fraction of martensite is high in the $45 \mathrm{deg}$ direction because of high Schmid factors in spite of low equivalent plastic strains, and is also high in the 0 and 90 deg directions because of low Schmid factors in spite of high equivalent plastic strains. Thus, it shows homogeneous distributions along the cup rim area (Figure 8(b)). In the A-DL steel, on the other hand, a number of martensites are formed in the 45 deg direction, although equivalent plastic strains are homogeneously distributed. According to McCoy and Ronevich et al. ${ }^{[25,50]}$ the deformation-induced $\gamma \rightarrow \alpha^{\prime}$-martensite transformation plays an important role in activating the hydrogen embrittlement by inducing much higher residual stresses than the austenite and by changing crystal structure to bcc having high diffusivity and low solubility of hydrogen. Residual stresses in the A-DL steel are homogeneously formed along the cup rim area, but the martensitic transformation is activated in the $45 \mathrm{deg}$ direction, along which the cracking occurs (Figure 6(d)).

Consequently, the delayed fracture is more critically affected by difference in deformation characteristics such as martensitic transformation and deformation inhomogeneity induced from concentration of residual stress or plastic strain, rather than the difference in microstructures in the DL and A-DL steels. The DL steel shows high planar anisotropy due to strongly banded structure, which induces the deformation inhomogeneity after the cup formation. The concentration of high residual stress and high volume fraction of $\alpha^{\prime}$-martensite due to highly localized plastic strain deteriorates delayed fracture properties. On the other hand, the A-DL steel shows homogeneous deformation behavior during the cup formation because of decomposed band structure, and thus the relatively low volume fraction of $\alpha^{\prime}$-martensite and uniform distribution of plastic strain and residual stress improve delayed fracture properties.

The batch annealing treatment prior to cold rolling is an effective way to modify microstructures and textures and to improve cup formability and delayed fracture properties by minimizing the deformation inhomogeneity and stress concentration. It can be useful to systematically understand delayed fracture mechanisms by microstructural evolution, planar anisotropy, and concentration of residual stress and plastic strain. The FEM and Schmid factor analyses and results are also outstanding ones, which have been hardly reported in previous studies on microscopic observation and delayed fracture behavior, because they are plausibly explained by the detailed microstructural evolution. Simultaneously, considering mechanical properties, delayed fracture properties, and costs of alloying elements as well as weight reduction effects required for automotive AHSS sheets, thus, the present A-DL steel can be fully adopted for automotive applications. In order to further enhance microstructures and properties of duplex lightweight steels, intensive studies on new 
alloy designs for improving formability, weldability, and productivity and on clarifying mechanisms involved in improved mechanical properties and delayed fracture properties should be continued in the future.

\section{CONCLUSIONS}

In the present study, effects of batch annealing treatment prior to cold rolling on delayed fracture properties of ferrite-austenite duplex lightweight steels were investigated in relation with microstructure, deformation inhomogeneity, and transformation characteristics.

1. The addition of batch annealing treatment at 1023 $\mathrm{K}\left(750^{\circ} \mathrm{C}\right)$ prior to cold rolling plausibly resulted in a modification of the microstructure. Ferrite grains were refined, and strong textures of $\{100\}\langle 011\rangle$ $\alpha$-fibers and $\{111\}\langle 112\rangle \gamma$-fibers were considerably dissolved, while the volume fraction and size of austenite were not varied much. Band structures were almost decomposed as austenite grains were relatively homogeneously distributed in the ferrite matrix.

2. Diffusible and non-diffusible hydrogen contents quantified by thermal desorption analysis were similar in both DL and A-DL steels, although the ferrite grain size was reduced in the A-DL steel. This result indicated that the effect of microstructural modification in the A-DL steels on hydrogen permeation was not significant.

3. The cup specimen of the DL steel showed a distinct earing phenomenon due to high intensity of $\{001\}\langle 110\rangle$ component texture and planar anisotropy, although the height of the cup specimen of the A-DL steel remained constant. The DL steel cup underwent the delayed fracture in the approximately 70 deg direction when immersed in a $0.1 \mathrm{M}$ $\mathrm{HCl}$ solution for 23 hours, whereas the A-DL steel cup was cracked in the random direction after 18 days. This result indicated that delayed fracture properties in the A-DL steel cup were much better than those of the DL steel cup.

4. The delayed fracture crack was initiated at regions of highly localized residual tensile stress or of high volume fraction of $\alpha^{\prime}$-martensite. The delayed fracture was more critically affected by difference in deformation characteristics such as martensitic transformation and deformation inhomogeneity induced from concentration of residual stress or plastic strain, rather than the difference in microstructures.

5. The high planar anisotropy of the DL steel induced the deformation inhomogeneity after the cup formation, and the highly localized plastic strain raised the concentration of residual stress and volume fraction of $\alpha^{\prime}$-martensite, which led to the deterioration of delayed fracture properties. On the other hand, the A-DL steel showed the homogeneous deformation behavior during the cup formation because of decomposed band structure, and, thus, the relatively low volume fraction of $\alpha^{\prime}$-martensite and uniform distribution of plastic strain and residual stress improved delayed fracture properties.

\section{ACKNOWLEDGMENTS}

This work was supported by the Ministry of Knowledge Economy under a Grant No. 10031723-2011-21 and BK21 Plus Center for Creative Industrial Materials.

\section{REFERENCES}

1. P.J. Jacques: Curr. Opin. Solid State Mater. Sci., 2004, vol. 8, pp. 259-65.

2. S. Zaefferer, J. Ohlert, and W. Bleck: Acta Mater., 2004, vol. 52, pp. 2765-78.

3. J. Bouquerel, K. Verbeken, and B.C. De Cooman: Acta Mater., 2006, vol. 54, pp. 1443-56.

4. D. Raabe, D. Ponge, O. Dmitrieva, and B. Sander: Scr. Mater., 2009, vol. 60, pp. 1141-44.

5. G. Frommeyer and U. Brüx: Steel Res. Int., 2006, vol. 77, pp. 627-33

6. R. Rana, C. Liu, and R.K. Ray: Scr. Mater., 2013, vol. 68, pp. 354-9.

7. S.W. Hwang, J.H. Ji, E.G. Lee, and K.T. Park: Mater. Sci. Eng. A, 2011, vol. 528, pp. 5196-5203.

8. B.-H. Song, J. Kim, S. Jeong, I. Choi, and Y.-K. Lee: Korean J. Met. Mater., 2014, vol. 52, pp. 1-9.

9. H. Kim, D.-W. Suh, and N.J. Kim: Sci. Technol. Adv. Mater., 2013, vol. 14, pp. 1-11.

10. D.-W. Suh, S.-J. Park, T.-H. Lee, C.-S. Oh, and S.-J. Kim: Metall. Mater. Trans. A, 2010, vol. 41A, pp. 397-408.

11. H. Huang, D. Gan, and P.W. Kao: Scr. Metall. Mater., 1994, vol. 30, pp. 499-504.

12. W.K. Choo, J.H. Kim, and J.C. Yoon: Acta Mater., 1997, vol. 45, pp. $4877-85$.

13. C.L. Lin, C.G. Chao, H.Y. Bor, and T.F. Liu: Mater. Trans., 2010, vol. 51, pp. 1084-88.

14. B.C. De Cooman, L. Chen, H.S. Kim, Y. Estrin, S.K. Kim, and H. Voswinckel: Microstructure and Texture in Steels, 1st ed., Springer, New York, 2009, p. 165.

15. K.-G. Chin, C.-Y. Kang, S.Y. Shin, S. Hong, S. Lee, H.S. Kim, K.-H. Kim, and N.J. Kim: Mater. Sci. Eng. A, 2011, vol. 528, pp. 2922-28.

16. O. Grässel, L. Krüger, G. Frommeyer, and L.W. Meyer: Int. J. Plast., 2000, vol. 16, pp. 1391-1409.

17. O. Bouaziz and N. Guelton: Mater. Sci. Eng. A, 2001, vol. 319, pp. 246-49.

18. M. Koyama, T. Sawaguchi, K. Ogawa, T. Kikuchi, and M. Murakami: Mater. Sci. Eng. A, 2008, vol. 497, pp. 353-57.

19. Y. Lou, S.J. Lim, and H. Huh: Met. Mater. Int., 2013, vol. 19, pp. 697-705.

20. J.S. Kim, Y.H. Lee, D.L. Lee, K.T. Park, and C.S. Lee: Mater. Sci. Eng. A, 2009, vol. 505, pp. 105-10.

21. M. Wang, E. Akiyama, and K. Tsuzaki: Scr. Mater., 2005, vol. 52, pp. 403-08.

22. J.E. Jin and Y.K. Lee: Acta Mater., 2012, vol. 60, pp. 1680-88.

23. J. Kim, S.-J. Lee, and B.C. De Cooman: Scr. Mater., 2011, vol. 65, pp. 363-66.

24. M.R. Berrahmoune, S. Berveiller, K. Inal, and E. Patoor: Mater. Sci. Eng. A, 2006, vols. 438-440, pp. 262-66.

25. R.A. McCoy: in International Conference on the Effects of Hydrogen on Materials Properties and Selection and Structural Design, I.M. Bernstein, A.W. Thompson, eds., ASM, 1973, pp. 169-78.

26. B. Kim, T.T.T. Trang, and N.J. Kim: Met. Mater. Int., 2014, vol. 20, pp. 35-39. 
27. J. Toribio and M. Elices: Int. J. Solids Structures, 1991, vol. 28, pp. 791-803.

28. ASTM E517-00: Standard Test Method for Plastic Strain Ratio $r$ for Sheet Metal, Annual Book of ASTM Standards, ASTM International, West Conshohocken, PA, 2000, vol. 03.01, pp. 1-8.

29. M. Wang, E. Akiyama, and K. Tsuzaki: Mater. Sci. Eng. A, 2005, vol. 398 , pp. 37-46.

30. S. Takagi, Y. Toji, M. Yoshino, and K. Hasegawa: ISIJ Int., 2012, vol. 52, pp. 316-22.

31. Y.S. Chun, K.-T. Park, and C.S. Lee: Scr. Mater., 2012, vol. 66, pp. $960-65$

32. S.S. Sohn, B.-J. Lee, J.-H. Kwak, and S. Lee: Metall. Mater. Trans. A, 2014, vol. 45A, pp. 3844-56.

33. S.S. Sohn, B.-J. Lee, S. Lee, N.J. Kim, and J.-H. Kwak: Acta Mater., 2013, vol. 61, pp. 5050-66.

34. A. Zargaran, H.S. Kim, J.-H. Kwak, and N.J. Kim: Scripta. Mater., 2014, vol. 89, pp. 37-40.

35. J. Ćwiek: J. Achiev. Mater. Manuf. Eng., 2009, vol. 37, pp. 193-212.

36. J.P. Hirth: Metall. Trans. A, 1980, vol. 11, pp. 861-90

37. I.-J. Park, S. Lee, H. Jeon, and Y.-K. Lee: Corros. Sci., 2014, vol. 93, pp. 63-69.

38. G.M. Pressouyre and I.M. Bernstein: Metall. Trans. A, 1978, vol. 9A, pp. 1571-80.
39. D. Raabe, Y. Wang, and F. Roters: Comput. Mater. Sci., 2005, vol. 34, pp. 221-34.

40. R.K. Saxena and P.M. Dixit: Int. J. Adv. Manuf. Technol., 2009, vol. 45 , pp. 219-33.

41. S.K. Singh, K. Mahesh, A. Kumar, and M. Swathi: Mater. Des., 2010, vol. 31, pp. 4478-84.

42. R. Hill: J. Mech. Phys. Solids, 1958, vol. 6, pp. 236-249.

43. Dassault Systemes, ABAQUS Online Documentation: Abaqus Analysis User's Manual, 2012.

44. I.N. Vladimirov, M.P. Pietryga, and S. Reese: Int. J. Plast., 2010, vol. 26, pp. 659-87.

45. E. Jimenez-Melero, N.H. van Dijk, L. Zhao, J. Sietsma, S.E. Offerman, J.P. Wright, and S. van der Zwaag: Scr. Mater., 2007, vol. 56 , pp. $421-24$.

46. C.-H. Seo, K.H. Kwon, K. Choi, K.-H. Kim, J.H. Kwak, S. Lee, and N.J. Kim: Scr. Mater., 2012, vol. 66, pp. 519-22.

47. L. Remy and A. Pineau: Mater. Sci. Eng. A, 1977, vol. 28, pp. 99-107.

48. J. Mahieu, J. Maki, B.C. De Cooman, and S. Claessens: Metall. Mater. Trans. A, 2002, vol. 33A, pp. 2573-80.

49. J.-S. Kim, J.B. Jeon, J.E. Jung, K.-K. Um, and Y.W. Chang: Met. Mater. Int., 2014, vol. 20, pp. 41-47.

50. J.A. Ronevich, B.C. De Cooman, J.G. Speer, E. De Moor, and D.K. Matlock: Metall. Mater. Trans. A, 2012, vol. 43A, pp. 2293-2301. 